\title{
Chemical ionization tandem mass spectrometer for the in situ measurement of methyl hydrogen peroxide
}

\author{
Jason M. St. Clair, ${ }^{1}$ David C. McCabe, ${ }^{1, a)}$ John D. Crounse, ${ }^{2}$ Urs Steiner, ${ }^{3, b)}$ and \\ Paul O. Wennberg ${ }^{1,4}$ \\ ${ }^{1}$ Division of Geological and Planetary Sciences, California Institute of Technology, \\ Pasadena, California 91125, USA \\ ${ }^{2}$ Division of Chemistry and Chemical Engineering, California Institute of Technology, \\ Pasadena, California 91125, USA \\ ${ }^{3}$ Varian, Inc., Santa Clara, California 95051, USA \\ ${ }^{4}$ Division of Engineering and Applied Science, California Institute of Technology, \\ Pasadena, California 91125, USA
}

(Received 6 April 2010; accepted 27 July 2010; published online 22 September 2010)

\begin{abstract}
A new approach for measuring gas-phase methyl hydrogen peroxide [(MHP) $\left.\mathrm{CH}_{3} \mathrm{OOH}\right]$ utilizing chemical ionization mass spectrometry is presented. Tandem mass spectrometry is used to avoid mass interferences that hindered previous attempts to measure atmospheric $\mathrm{CH}_{3} \mathrm{OOH}$ with $\mathrm{CF}_{3} \mathrm{O}^{-}$ clustering chemistry. $\mathrm{CH}_{3} \mathrm{OOH}$ has been successfully measured in situ using this technique during both airborne and ground-based campaigns. The accuracy and precision for the MHP measurement are a function of water vapor mixing ratio. Typical precision at 500 pptv $\mathrm{MHP}$ and $100 \mathrm{ppmv} \mathrm{H}_{2} \mathrm{O}$ is $\pm 80 \mathrm{pptv}$ ( 2 sigma) for a $1 \mathrm{~s}$ integration period. The accuracy at $100 \mathrm{ppmv} \mathrm{H}_{2} \mathrm{O}$ is estimated to be better than $\pm 40 \%$. Chemical ionization tandem mass spectrometry shows considerable promise for the determination of in situ atmospheric trace gas mixing ratios where isobaric compounds or mass interferences impede accurate measurements. (c) 2010 American Institute of Physics.
\end{abstract}

[doi:10.1063/1.3480552]

\section{INTRODUCTION}

Hydrogen peroxide $\left(\mathrm{H}_{2} \mathrm{O}_{2}\right)$ and methyl hydrogen peroxide (MHP, $\left.\mathrm{CH}_{3} \mathrm{OOH}\right)$ are the two most abundant hydroperoxides in the troposphere. The formation of $\mathrm{H}_{2} \mathrm{O}_{2}$ and $\mathrm{CH}_{3} \mathrm{OOH}$ occurs via reactions (1) and (2).

$$
\begin{aligned}
& \mathrm{HO}_{2}+\mathrm{HO}_{2} \rightarrow \mathrm{H}_{2} \mathrm{O}_{2}+\mathrm{O}_{2}, \\
& \mathrm{CH}_{3} \mathrm{O}_{2}+\mathrm{HO}_{2} \rightarrow \mathrm{CH}_{3} \mathrm{OOH}+\mathrm{O}_{2} .
\end{aligned}
$$

Primary loss mechanisms for both hydroperoxides include photolysis and reaction with $\mathrm{OH}$

$$
\begin{aligned}
& \mathrm{H}_{2} \mathrm{O}_{2}+\mathrm{h} \nu \rightarrow 2 \mathrm{OH} \\
& \mathrm{CH}_{3} \mathrm{OOH}+\mathrm{h} \nu \rightarrow \mathrm{CH}_{3} \mathrm{O}+\mathrm{OH} \\
& \mathrm{CH}_{3} \mathrm{O}+\mathrm{O}_{2} \rightarrow \mathrm{HO}_{2}+\mathrm{CH}_{2} \mathrm{O} \\
& \mathrm{H}_{2} \mathrm{O}_{2}+\mathrm{OH} \rightarrow \mathrm{HO}_{2}+\mathrm{H}_{2} \mathrm{O} \\
& \mathrm{CH}_{3} \mathrm{OOH}+\mathrm{OH} \rightarrow \mathrm{CH}_{3} \mathrm{O}_{2}+\mathrm{H}_{2} \mathrm{O} \\
& \left.\quad \rightarrow \mathrm{CH}_{2} \mathrm{O}+\mathrm{OH}+\mathrm{H}_{2} \mathrm{O} \quad \text { (via } \mathrm{CH}_{2} \mathrm{OOH}\right) .
\end{aligned}
$$

$\mathrm{H}_{2} \mathrm{O}_{2}$ is also lost via wet and dry deposition. ${ }^{1,2}$ The transport of $\mathrm{H}_{2} \mathrm{O}_{2}$ and $\mathrm{CH}_{3} \mathrm{OOH}$ and the subsequent release of $\mathrm{HO}_{\mathrm{x}}$ and $\mathrm{CH}_{2} \mathrm{O}\left(\mathrm{a} \mathrm{HO}_{\mathrm{x}}\right.$ precursor) necessitates the inclusion of

\footnotetext{
${ }^{a)}$ Present address: Clean Air Task Force, Boston, Massachusetts, USA.

${ }^{b)}$ Present address: PerkinElmer, Inc., Branford, Connecticut, USA.
}

hydroperoxides in $\mathrm{HO}_{x}$ and $\mathrm{O}_{3}$ budgets, particularly for the upper troposphere (UT) ${ }^{3-5}$ Convective systems rapidly transport boundary layer air up into the UT, affecting the chemical balance of the UT through enhancements of photochemically active species, including hydroperoxides. ${ }^{5,6} \mathrm{H}_{2} \mathrm{O}_{2}$ has a higher removal rate via convective processing than $\mathrm{CH}_{3} \mathrm{OOH}$ due to its much larger Henry's Law coefficient $\left(8.33 \times 10^{4}\right.$ and $311 \mathrm{M} / \mathrm{atm}$, respectively, at $\left.298 \mathrm{~K}\right) .{ }^{1}$ Consequently, an increase in $\left[\mathrm{CH}_{3} \mathrm{OOH}\right]$ relative to $\left[\mathrm{H}_{2} \mathrm{O}_{2}\right]$ can be used to identify recent convective activity. ${ }^{7-9}$

The most common technique for the measurement of atmospheric gas phase $\mathrm{H}_{2} \mathrm{O}_{2}$ and $\mathrm{CH}_{3} \mathrm{OOH}$ involves transferring the hydroperoxides into the aqueous phase followed by chemical derivatization and detection via fluorescence. ${ }^{10}$ Separation of the constituent hydroperoxides by highperformance liquid chromatography is often performed on the aqueous sample before derivatization. Drawbacks to the fluorescence technique include a slow instrumental time response (often minutes) and the potential for interference from aqueous chemistry, e.g., hydroperoxide reaction with $\mathrm{SO}_{2} \cdot{ }^{10}$ We have successfully utilized the chemical ionization mass spectrometry (CIMS) for the in situ detection of $\mathrm{H}_{2} \mathrm{O}_{2}$ as described in Crounse et al., ${ }^{11}$ with an instrument time response of $<1 \mathrm{~s}$ and a possible data rate of $8 \mathrm{~Hz}$ or higher. The measurement of $\mathrm{H}_{2} \mathrm{O}_{2}$ and other trace species by the Caltech single quadrupole CIMS instrument using $\mathrm{CF}_{3} \mathrm{O}^{-}$ negative ion chemistry followed from previous works with similar ion chemistry. ${ }^{12-14}$ The negative ion cluster chemistry of $\mathrm{CF}_{3} \mathrm{O}^{-}$with $\mathrm{H}_{2} \mathrm{O}_{2}$ provides a signal at a mass-to-charge ratio $(\mathrm{m} / \mathrm{z})=119$, unencumbered by significant mass interfer- 


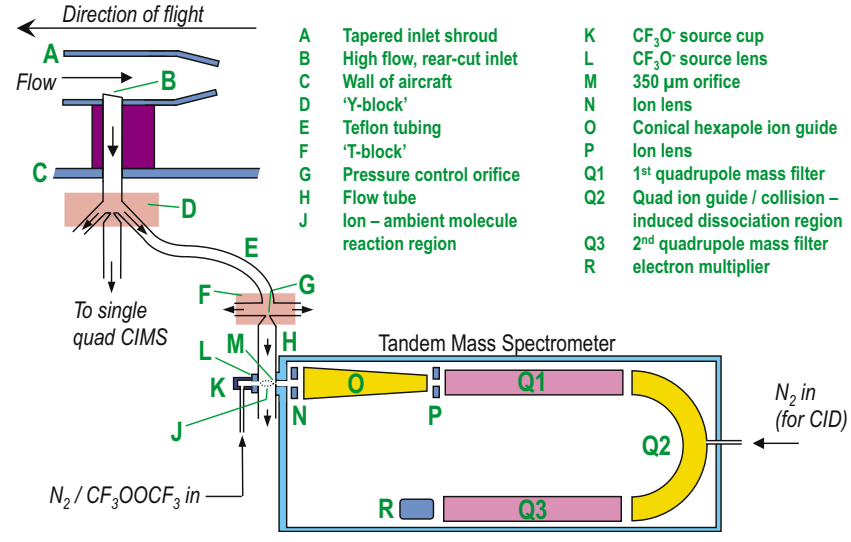

FIG. 1. (Color online) Triple quadrupole CIT CIMS instrument schematic aboard the NASA DC-8.

ences. However, the detection of $\mathrm{CH}_{3} \mathrm{OOH}$ by the same ion chemistry is complicated by a background signal at $\mathrm{m} / \mathrm{z}$ $=133$ that is unrelated to $\left[\mathrm{CH}_{3} \mathrm{OOH}\right]$. $^{11}$

We have developed a new CIMS instrument for the detection of $\mathrm{CH}_{3} \mathrm{OOH}$ and other trace species that utilizes the same ion chemistry while being largely immune to mass interferences described previously. ${ }^{11}$ The new instrument employs tandem mass spectrometry (MS) to differentiate isobaric ionized species by decomposing the parent ion into daughter fragments that uniquely identify each species if their respective daughter ion spectra are distinct. The tandem MS (or triple quadrupole) instrument has participated in three aircraft campaigns: aboard the NSF C-130 during MILAGRO/INTEX-B in 2006, and aboard the NASA DC-8 during TC4 in 2007 and ARCTAS in 2008 (see Fast et al., ${ }^{15}$ Toon, ${ }^{16}$ and Jacob, ${ }^{17}$ respectively, for mission details). The tandem MS instrument also participated in the ground-based summer 2009 BEARPEX campaign. In this paper, we describe the tandem MS CIMS instrument as well as present in situ data showing the benefit of tandem MS for the measurement of methyl hydrogen peroxide by CIMS.

\section{INSTRUMENT DESCRIPTION}

The Caltech triple quadrupole CIMS instrument consists of a custom chemical ionization source coupled to the mass spectrometer from a commercial Varian 1200 GCMS system (Palo Alto, CA). The ion source and ion chemistry have been described previously for the Caltech single quadrupole CIMS instrument, ${ }^{11}$ so only a brief description is included below. The Varian 1200 contains three quadrupoles: two used for mass filtration and one for collision-induced dissociation. The instrument can be operated in single MS or tandem MS (MSMS) mode, although in flight, it is typically run only in MSMS mode due to the time required to switch between the two modes. The instrument can also be operated in a positive ion mode similar to a proton transfer reaction mass spectrometer, though this ability has only been exploited in the laboratory ${ }^{18}$ and not in field experiments.

A schematic of the Caltech triple quadrupole CIMS instrument is shown in Fig. 1. The DC-8 aircraft inlet is described in Crounse et al. ${ }^{11}$ and is shown schematically in Fig. 1 (A-C). The triple quadrupole CIMS samples from one of the two bypass flows from the single quadrupole instrument Y-block (Fig. 1, D). ${ }^{11}$ From the Y-block, the flow travels through $1.57 \mathrm{~m}$ of $2.54 \mathrm{~cm}$ outer diameter (OD) Teflon perfluoroalkoxy polymer (PFA) tubing (Fig. 1, E) at a flow of $\sim 10$ standard liters per second to a T-block (Fig. 1, F) mounted atop the mass spectrometer. The majority of the flow into the T-block exits as bypass flow through two ports on opposite sides of the block, as only a small portion $\sim 600$ standard cubic centimeters per minute (SCCM) is analytically sampled. The sample flow enters the flow tube through an adjustable pinhole orifice plate (Fig. 1, G) that regulates the flow via software control of a stepper motor to maintain a constant $35 \mathrm{hPa}$ pressure (and approximately constant analytical sample mass flow) in the flow tube. The $2.54 \mathrm{~cm}$ OD, $11.7 \mathrm{~cm}$ long glass flow tube (Fig. 1, H) connects the T-block to the ion source block, delivering the sample flow to the ion/molecule reaction region (Fig. 1, J). The flow tube is coated with a fluoropolymer (Fluoropel PFC 801A, Cytonix, Beltsville, MD) to minimize the wall uptake and release of water and other analytes. The analytical flow is diluted $\sim 1: 2$ by the addition of a constant 1.2 standard liters per minute flow of ultrahigh purity (UHP) $\mathrm{N}_{2}$ on the low-pressure side of the T-block. The decrease in water mixing ratio upon dilution improves the instrument sensitivity for MHP, which exhibits monotonically decreasing sensitivity with increasing water and decreases instrumental backgrounds from water clusters. Calibration gases are also introduced at the lowpressure side of the T-block during calibration cycles. All flow controllers used in the instrument are piezoelectricactuated with all-metal seals (HORIBA STEC, Austin, TX).

The reagent ion for the chemical ionization is produced by flowing $400 \mathrm{SCCM}$ of $10 \mathrm{ppmv} \mathrm{CF}_{3} \mathrm{OOCF}_{3}$ in UHP $\mathrm{N}_{2}$ into a cylindrical source cup (Fig. 1, K) lined with a foil containing Po-210 (NRD LLC, $\leq 4.5 \mathrm{mCi}$ ). Alpha particles emitted by the Po- 210 begin a series of reactions that ultimately yield the reagent ion $\mathrm{CF}_{3} \mathrm{O}^{-}$. A $30 \mathrm{~V}$ potential between the source cup and source lens (Fig. 1, L) accelerates $\mathrm{CF}_{3} \mathrm{O}^{-}$ions into the ion/molecule reaction region where they can react with analytes. $\mathrm{CH}_{3} \mathrm{OOH}$ forms a cluster with the reagent ion

$$
\mathrm{CF}_{3} \mathrm{O}^{-}+\mathrm{CH}_{3} \mathrm{OOH}+\mathrm{M} \rightarrow \mathrm{CF}_{3} \mathrm{O}^{-} \cdot \mathrm{CH}_{3} \mathrm{OOH}+\mathrm{M},
$$

where $\mathrm{M}$ is a $\mathrm{N}_{2}$ or an $\mathrm{O}_{2}$ molecule. Typical voltages for the source cup and source lens are -330 and $-300 \mathrm{~V}$, respectively, with the orifice into the mass spectrometer at $0 \mathrm{~V}$. The potential between the source lens and the orifice directs ions toward the orifice, moving the ions perpendicular to the sample flow. Note that all voltages listed below are relative to ground rather than to adjacent ion optics.

Product ions enter the mass spectrometer through the $350 \mu \mathrm{m}$ orifice (Fig. 1, M), passing through a lens (Fig. 1, N) before reaching the conical hexapole ion guide (Fig. 1, O). The lens serves to shield the orifice from the hexapole and both the lens and the orifice are held at $0 \mathrm{~V}$. The hexapole is mounted in the chamber that originally housed the ionization source for the commercial instrument. The conical hexapole is driven at $1.638 \mathrm{MHz}$ by the radio 
frequency (RF) supply used to operate the original hexapole ion guide in the Varian 1200 and typically is biased by $+1.2 \mathrm{~V}$.

The conical hexapole is composed of six $16.6 \mathrm{~cm}$ long conical stainless steel rods with end diameters of 7.1 and 2.4 $\mathrm{mm}$. The rods are arranged in a circular pattern that begins with an inner diameter (ID) of $14.2 \mathrm{~mm}$ for the larger diameter rod ends near the lens. The ID of the hexapole narrows to $4.8 \mathrm{~mm}$ at the smaller diameter rod ends. The ion beam exits the hexapole chamber via a $4 \mathrm{~mm}$ aperture (Fig. 1, P), held at $+2.4 \mathrm{~V}$ (for $\mathrm{m} / \mathrm{z}=133 \rightarrow \mathrm{m} / \mathrm{z}=85$, as are all of the subsequent ion optic voltages). The pressure in the hexapole chamber is typically $4.7 \times 10^{-3} \mathrm{hPa}$.

The first mass selection is performed by the first quadrupole mass filter (Fig. 1, Q1). Q1 is usually set to a $0.7 \mathrm{amu}$ full-width half maximum (FWHM) mass resolution with an average potential of $+3.4 \mathrm{~V}$. Ions that are selected by Q1 pass through to the collision-induced dissociation (CID) chamber (Fig. 1, Q2), consisting of a partially enclosed rfonly quadrupole with a small flow of $\mathrm{N}_{2}$ that yields a CID pressure of $2.7 \times 10^{-3} \mathrm{hPa}$. Collisions of ions with $\mathrm{N}_{2}$ in Q2 cause fragmentation of the analyte ions with the fragment yield dependent on the CID pressure and the collision energetics. The third quadrupole (Fig. 1, Q3), with a typical mass resolution of 1.5 amu FWHM, filters for a specific daughter ion produced by the CID. The voltage between Q1 and Q2 is adjusted to optimize the yield of the desired daughter ion. In the case of $\mathrm{CH}_{3} \mathrm{OOH}, \mathrm{Q} 2$ is set to $+6.4 \mathrm{~V}$. CID decomposes the ion cluster

$\mathrm{CF}_{3} \mathrm{O}^{-} \cdot \mathrm{CH}_{3} \mathrm{OOH}(\mathrm{m} / \mathrm{z}=133)+\mathrm{CID} \rightarrow \mathrm{CF}_{3} \mathrm{O}^{-}(\mathrm{m} / \mathrm{z}=85)$,

with Q3 passing $\mathrm{m} / \mathrm{z}=85$ to the electron multiplier detector (Fig. 1, R). Q3 is held at $+7.0 \mathrm{~V}$ and the voltage across the electron multiplier is $2 \mathrm{kV}$. The pressure in the main chamber is $6.7 \times 10^{-5} \mathrm{hPa}$ while the CID gas is flowing. The pumping on the hexapole chamber and the main chamber is performed by a split flow Edwards EXT200/200H turbomolecular pump (Tewksbury, MA).

Data for the triple quadrupole CIMS instrument are collected on two computer systems. Control and data collection for the mass spectrometer are conducted by the software provided by Varian, along with supplemental scripts written inhouse. Gas flows, ion source voltages, pump and valve controls, and environmental parameters are controlled and recorded by a Diamond Systems Hercules II (Mountain View, CA) running the QNX real-time operating system (version 4.25) with custom software. Communication between the two computer systems, necessary for synchronizing data collection, is achieved via 3 bits from QNX to Windows that enable/disable MS data collection, select source polarity, and select scan or hop mode for $\mathrm{m} / \mathrm{z}$ selection; 2 bits from Windows to QNX indicate the status of MS data collection.

\section{INSTRUMENT OPERATION}

The data collection rate for a given $\mathrm{m} / \mathrm{z}$ is dependent on the number of other masses monitored and the amount of time spent on each mass. The time spent on a given mass varies from mass to mass, between 0.125 and $1 \mathrm{~s}$ in multiples of $0.125 \mathrm{~s}$, and was chosen in consideration of the signal to noise ratio at that mass. For example, $\mathrm{CH}_{3} \mathrm{OOH}$ data might be collected for $1 \mathrm{~s}$ every $30 \mathrm{~s}$. The base unit of $0.125 \mathrm{~s}$ is arbitrary. It is important to note that data reported from instruments operated in this manner contain no information about a given mass in the air sampled while the instrument is not measuring that mass.

The electron multiplier in the Varian 1200 provides an analog signal to an analog-to-digital converter (ADC) for data collection, in contrast to the single quadrupole CIMS instrument where the electron multiplier is operated in pulse counting mode. Each $0.125 \mathrm{~s}$ segment is comprised of 1531 samples of the ADC (one every $82 \mu \mathrm{s}$ ), which are averaged to give the analog signal in millivolts. The instrument requires the data to be collected over a scan, so the 1531 samples span a 0.1 amu Q3 window centered on the daughter $\mathrm{m} / \mathrm{z}$.

A software ion-counting method is used to improve the sensitivity of the instrument at low signal levels. The signal for each of the 1531 samples is compared in the software to a preset threshold and if the signal exceeds the threshold, then a count is recorded. The two subsequent samples are ignored to avoid double-counting the same ion. The number of counts tallied over the 1531 samples is recorded as the raw digital signal per $1 / 8 \mathrm{~s}$. This digital signal and the analog signal are subjected to postflight data processing before being combined into one data set, as described below.

\section{A. Backgrounds and in-flight calibrations}

The measurement of MHP by single MS is hindered by $\mathrm{m} / \mathrm{z}=133$ signal from ions [e.g., $\mathrm{CF}_{3} \mathrm{C}(\mathrm{O}) \mathrm{O}^{-} \cdot \mathrm{HF}$ and $\left.\mathrm{Si}\left(\mathrm{CH}_{3}\right)_{2} \mathrm{~F}_{3}^{-} \cdot \mathrm{H}_{2} \mathrm{O}\right]$ that are produced in the ion source from impurities in the reagent gas $\left(\mathrm{CF}_{3} \mathrm{OOCF}_{3}\right)$ flow. The measurement of MHP by tandem MS is largely immune from significant instrumental backgrounds because the interfering ions do not yield $\mathrm{m} / \mathrm{z}=85$ upon collision-induced dissociation. Instrumental backgrounds are measured on a regular basis with a dry zero every $110 \mathrm{~min}$ and an ambient zero every $20 \mathrm{~min}$. During a dry zero, the T-block orifice closes to end sampling of ambient air and the dilution $\mathrm{N}_{2}$ flow is increased in compensation to maintain $35 \mathrm{hPa}$ in the flow tube. During the ambient zero, the balance of flow is instead provided with ambient air that is first passed through a scrubber consisting of Pd-coated alumina pellets and an annular glass substrate coated with $\mathrm{NaHCO}_{3}$. The scrubber quantitatively removes peroxides while passing $\mathrm{H}_{2} \mathrm{O}$. In-flight calibrations are typically performed every $45 \mathrm{~min}$ with an ambient zero flow and every 110 min with a dry zero flow. The in-flight calibration system is described in Crounse et al. ${ }^{11}$ The calibration species typically included are $\mathrm{H}_{2} \mathrm{O}_{2}, \mathrm{CH}_{3} \mathrm{OOH}$, peroxyacetic acid $\left[\mathrm{CH}_{3} \mathrm{C}(\mathrm{O}) \mathrm{OOH}\right]$, and isotopically labeled nitric, formic, and acetic acids. ${ }^{19}$

\section{DATA ANALYSIS}

The analog and the digital count data require postcollection processing before the data are analyzed. A counting correction is applied to the digital count data to account for 
multiple ions arriving at the detector within the same counting window. The analog signal is corrected for detector baseline drift by subtracting a baseline from the analog data. The baseline is obtained by interpolating the analog signal measured when the digital count rate is zero. The data carried forward in the analysis are a combination of the analog and digital count data: digital count data are used up to 200 counts per $1 / 8 \mathrm{~s}$ and the analog data are used when the count rate is higher. Data with $<200$ counts per $1 / 8 \mathrm{~s}$ are fit to a line and the slope is applied as a scaling factor to the higher signal analog data before combining the analog and digital data into a single data set, expressed as an ion count. Consecutive $1 / 8 \mathrm{~s}$ data points with the same $\mathrm{m} / \mathrm{z}$ ( 8 data points for MHP) are then averaged using the combined analog/ digital data. As a consequence, all count rates presented for the tandem MS instrument are in 1/8 s time units.

The data are normalized to the ${ }^{13} \mathrm{C}$ reagent ion signal, taken as ${ }^{13} \mathrm{CF}_{3} \mathrm{O}^{-}(\mathrm{m} / \mathrm{z}=86)+{ }^{13} \mathrm{CF}_{3} \mathrm{O}^{-} \cdot \mathrm{H}_{2} \mathrm{O} \quad(\mathrm{m} / \mathrm{z}=104)$. Signal levels at the ${ }^{12} \mathrm{C}$ reagent ion masses $(\mathrm{m} / \mathrm{z}=85$ and $\mathrm{m} / \mathrm{z}=103)$ are too high to safely measure without decreasing the detector gain. Typical rates for $\mathrm{m} / \mathrm{z}=86 \rightarrow \mathrm{m} / \mathrm{z}=86$ in dry air are $1500 \mathrm{cts}$ per $1 / 8 \mathrm{~s}$. Normalizing to the reagent ion signal is necessary to correct for changes in reagent ion mixing ratio in the flow tube, as well as changes in instrumental ion throughput (generally $< \pm 7 \%$ ). "Normalized ion counts" refer to the data after this correction is applied.

The periodic dry and ambient zero data are used to obtain a background signal for each analyte. The approach used to obtain the background for a given species varies, depending on factors such as the efficiency of the ambient scrubber in removing the species and whether the background signal exhibits a water-dependence. For MHP measured by tandem MS, the background signal is small and stable enough that an interpolation of the zero data is sufficient to represent the instrument background. After the background is subtracted, the water-dependent sensitivity curve for the analyte is applied using the water cluster masses $\mathrm{m} / \mathrm{z}=104$ and $\mathrm{m} / \mathrm{z}$ $=121\left[{ }^{12} \mathrm{CF}_{3} \mathrm{O}^{-} \cdot\left(\mathrm{H}_{2} \mathrm{O}\right)_{2}\right]$ or the water measurement available for the flight [e.g., the NASA Langley Diode Laser Hygrometer $\left.(\mathrm{DLH})^{20}\right]$, with a dilution factor applied to account for the decrease from ambient to flow tube humidity. The calculated analyte flow-tube mixing ratio is then corrected for dilution to obtain the ambient mixing ratio.

\section{LABORATORY CALIBRATION}

Laboratory calibrations for $\mathrm{CH}_{3} \mathrm{OOH}$ and $\mathrm{H}_{2} \mathrm{O}_{2}$ are performed by introducing the output of a stable peroxide source and measuring the ion signal as a function of flow tube water mixing ratio. Figure 2 shows the $\mathrm{CH}_{3} \mathrm{OOH}$ and $\mathrm{H}_{2} \mathrm{O}_{2}$ sensitivity curves for the tandem instrument, with ion signal plotted as a function of flow tube water mixing ratio. The ion signal is shown normalized to the ${ }^{13} \mathrm{C}$ reagent ion signal as explained in Sec. IV. The details of the peroxide calibrations are enumerated in Crounse et al. ${ }^{11} \mathrm{In}$-flight calibrations are performed using a temperature-controlled diffusion vial as the $\mathrm{CH}_{3} \mathrm{OOH}$ source and urea hydrogen peroxide as the $\mathrm{H}_{2} \mathrm{O}_{2}$ source. The same peroxide sources are used for laboratory calibrations. Additional laboratory calibrations for

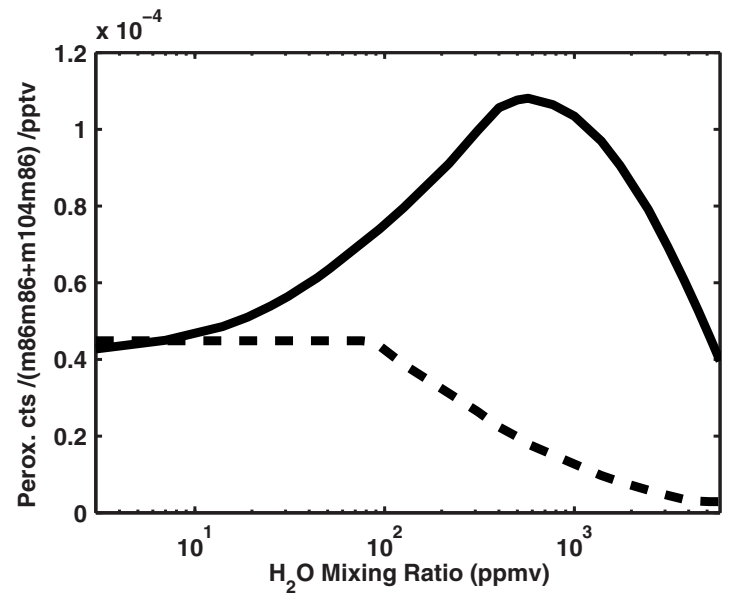

FIG. 2. Sensitivity curves for $\mathrm{CH}_{3} \mathrm{OOH} \mathrm{m} / \mathrm{z}=133 \rightarrow \mathrm{m} / \mathrm{z}=85$ (dashed line) and $\mathrm{H}_{2} \mathrm{O}_{2} \mathrm{~m} / \mathrm{z}=119 \rightarrow \mathrm{m} / \mathrm{z}=85$ (solid line) as a function of the water mixing ratio in the instrument flow tube.

$\mathrm{CH}_{3} \mathrm{OOH}$ are performed with a larger source consisting of $\mathrm{CH}_{3} \mathrm{OOH}$ in a $6.4 \mathrm{~mm}$ OD glass vial held at room temperature. Dry $\mathrm{N}_{2}$ is passed over top of the vial and into a single pass optical cell for mixing ratio determination by Fourier transform-IR absorption. ${ }^{21}$ The output of the optical cell is then diluted and introduced into the CIMS flow tube. The output of all $\mathrm{CH}_{3} \mathrm{OOH}$ and $\mathrm{H}_{2} \mathrm{O}_{2}$ sources are determined by a colorimetric technique (Bioxytech $\mathrm{H}_{2} \mathrm{O}_{2}-560$, Bio-Stat Research).

\section{FIELD DATA}

To illustrate the benefit of tandem MS in reducing signal backgrounds, Fig. 3 displays the $\mathrm{m} / \mathrm{z}=133$ normalized ion counts from both Caltech CIMS instruments and MHP mixing ratios from the tandem MS instrument for one flight (April 19, 2008) during the spring ARCTAS campaign. Figures 3(a) and 3(b) show the normalized counts for $\mathrm{m} / \mathrm{z}$ $=133$ (single quadrupole CIMS) and $\mathrm{m} / \mathrm{z}=133 \rightarrow \mathrm{m} / \mathrm{z}=85$
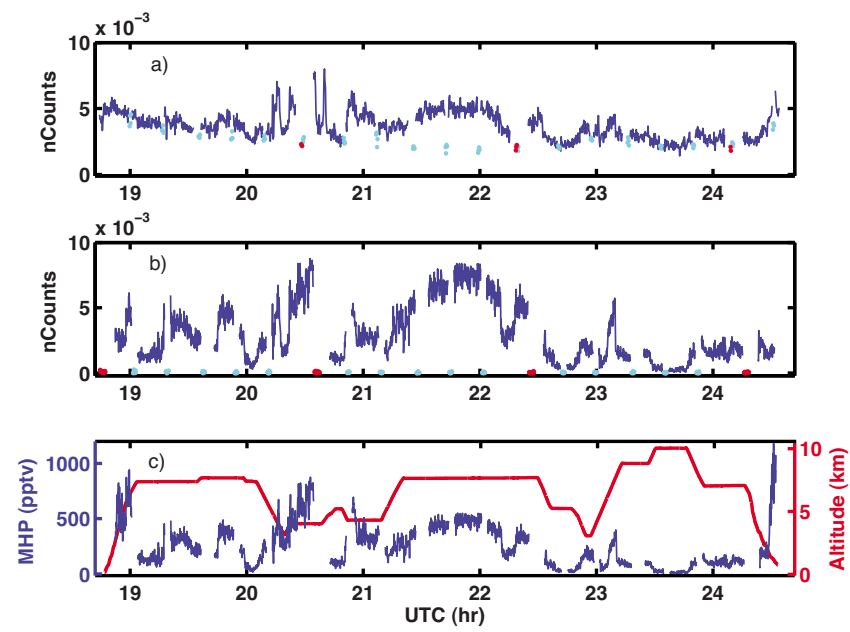

FIG. 3. (Color online) ARCTAS flight of 19 April 2008. Top panel: normalized counts of $\mathrm{m} / \mathrm{z}=133$ for the single quadrupole CIMS. The line is data, dark points are dry zero, and light points are ambient zero. Middle panel: normalized counts of $\mathrm{m} / \mathrm{z}=133 \rightarrow \mathrm{m} / \mathrm{z}=85$ for the triple quadrupole CIMS. Bottom panel: MHP mixing ratio as determined by the triple quadrupole CIMS (thin line) and aircraft altitude (thick line). 
(triple quadrupole CIMS), with the ambient data shown as the line and the zeros shown as dark points (dry zero) and light points (ambient zero). The single quadrupole CIMS collected data at $\mathrm{m} / \mathrm{z}=133$ for $1 / 8 \mathrm{~s}$ every $15 \mathrm{~s}$ while the triple quadrupole CIMS collected data at $\mathrm{m} / \mathrm{z}=133 \rightarrow \mathrm{m} / \mathrm{z}=85$ for $1 \mathrm{~s}$ every $8 \mathrm{~s}$. The zeros for the single quadrupole CIMS are substantial in comparison to the ambient data signal and they vary over the duration of the flight. The zeros for the triple quadrupole CIMS instrument, in contrast, are consistently an order of magnitude lower than the ambient data signal. The difference in the relative magnitude of the zeros for the two instruments makes determining MHP mixing ratios straightforward for the triple quadrupole CIMS and very difficult for the single quadrupole instrument. Triple quadrupole CIMS MHP data for the flight, determined by subtraction of the zeros and application of the water-dependent sensitivity curve, is also shown in Fig. 3(c). Aircraft altitude is included for reference.

\section{ACCURACY AND PRECISION}

The uncertainty in the in situ measurement of MHP by the triple quadrupole CIMS instrument is dominated by the uncertainty in the water-dependent sensitivity curve used to calculate MHP mixing ratios. Uncertainty in the sensitivity curve is a combination of instrumental precision, accuracy in the absolute quantification of the MHP calibration source, and accuracy in the quantification of the water mixing ratio in the flow tube during calibration. At high flow tube water mixing ratios, the sensitivity of the instrument to MHP is greatly diminished as seen in Fig. 2. The lower sensitivity results in greater uncertainty in $\left[\mathrm{CH}_{3} \mathrm{OOH}\right]_{\text {ambient }}$ at high water mixing ratios. Uncertainty in the determination of the flow tube water mixing ratio, during both calibration and ambient air sampling, contributes to the uncertainty in the MHP measurement because the instrument sensitivity to MHP varies with water and any error in $\left[\mathrm{H}_{2} \mathrm{O}\right]_{\text {flow tube }}$ results in an error in $\left[\mathrm{CH}_{-} 3 \mathrm{OOH}\right]_{\text {ambient }}$. For the ARCTAS campaign, we determined the $95 \%$ confidence interval measurement uncertainty to be the following function of ambient $\left[\mathrm{H}_{2} \mathrm{O}\right]$ :

$\pm\{50 \mathrm{pptv}+$

$\mathrm{DLH}=0-230$ ppmv: $40 \%$ of $\mathrm{MHP}$;

DLH > 230 ppmv:

$$
\left.\left[-9.1+20.8^{*} \log _{10}(\mathrm{DLH})\right] \% \text { of } \mathrm{MHP}\right\}
$$

where "DLH" is the ambient water mixing ratio in ppmv as measured by the DLH instrument. The 50 pptv term is included to account for the possible introduction of a bias by the subtraction of the instrumental background and is only significant at low MHP mixing ratios. At higher MHP mixing ratios, the uncertainty ranges from $\pm 40 \%$ to $\pm 80 \%$ at high water. Because the measurement uncertainty is dominated by the accuracy, time-averaging data does not reduce the uncertainty. The precision at 500 pptv $\mathrm{MHP}$ and $100 \mathrm{ppmv}_{2} \mathrm{O}$ is $\pm 80 \mathrm{pptv}$ (2 sigma) for a $1 \mathrm{~s}$ integration period.

\section{CONCLUSIONS}

MHP can be quantified rapidly and precisely with $\mathrm{CF}_{3} \mathrm{O}^{-}$ CIMS using tandem MS to distinguish MHP signal from mass interferences at $\mathrm{m} / \mathrm{z}=133$. Like the single quadrupole CIMS instrument, the tandem MS instrument possesses the high sensitivity and rapid time response that is necessary for high spatial resolution in situ sampling from aircraft. In addition, the tandem MS instrument opens up the possibility of measuring atmospheric species that are otherwise not measurable, either by separating mass interferences, differentiating between isobaric compounds, or elucidating chemical structures by analyzing parent-daughter fragmentation patterns. The tandem MS instrument achieves a typical precision of \pm 80 pptv (2 sigma) at 500 pptv MHP and 100 ppmv $\mathrm{H}_{2} \mathrm{O}$ for a $1 \mathrm{~s}$ integration period and a measurement accuracy better than $\pm 40 \%$ at 100 ppmv $\mathrm{H}_{2} \mathrm{O}$.

\section{ACKNOWLEDGMENTS}

We thank James Oliver for support with mechanical designs used for the fabrication of custom parts in this instrument as well as parts needed for integration onto the aircraft and Norton Allen for support with the QNX-based control/ data-collection software. We also thank NCAR/NSF C-130 and NASA DC-8 aircraft crew, pilots, and engineers and support staff for assistance with integration of instrumentation onto aircraft and for successful completion of science missions. Funding for this research was provided by the NASA Tropospheric Chemistry Program. This instrument would have not been possible without the financial support of Caltech trustee William Davidow. J.D.C. acknowledges EPA-STAR Fellowship Program (Contract No. FP916334012) support. This work has not been formally reviewed by the EPA. The views expressed in this document are solely those of the authors and the EPA does not endorse any products or commercial services mentioned in this publication.

${ }^{1}$ D. W. O'Sullivan, M. Y. Lee, B. C. Noone, and B. G. Heikes, J. Phys. Chem. 100, 3241 (1996).

${ }^{2}$ J. Valverde-Canossa, L. Ganzeveld, B. Rappengluck, R. Steinbrecher, O. Klemm, G. Schuster, and G. K. Moortgat, Atmos. Environ. 40, 55 (2006).

${ }^{3}$ D. J. Jacob, M. J. Prather, P. J. Rasch, R. L. Shia, Y. J. Balkanski, S. R. Beagley, D. J. Bergmann, W. T. Blackshear, M. Brown, M. Chiba, M. P. Chipperfield, J. de Grandpre, J. E. Dignon, J. Feichter, C. Genthon, W. L. Grose, P. S. Kasibhatla, I. Kohler, M. A. Kritz, K. Law, J. E. Penner, M. Ramonet, C. E. Reeves, D. A. Rotman, D. Z. Stockwell, P. F. J. Van Velthoven, G. Verver, O. Wild, H. Yang, and P. Zimmermann, J. Geophys. Res., [Atmos.] 102, 5953 (1997).

${ }^{4}$ M. J. Prather and D. J. Jacob, Geophys. Res. Lett. 24, 3189 (1997).

${ }^{5}$ L. Jaeglé, D. J. Jacob, W. H. Brune, and P. O. Wennberg, Atmos. Environ. 35, 469 (2001).

${ }^{6}$ M. C. Barth, S. W. Kim, W. C. Skamarock, A. L. Stuart, K. E. Pickering, and L. E. Ott, J. Geophys. Res., [Atmos.] 112, D13310 (2007).

${ }^{7}$ B. G. Heikes, M. Lee, J. Bradshaw, S. Sandholm, D. D. Davis, J. Crawford, J. Rodriguez, S. Liu, S. McKeen, D. Thornton, A. Bandy, G. Gregory, R. Talbot, and D. Blake, J. Geophys. Res., [Atmos.] 101, 1891 (1996).

${ }^{8}$ D. S. Cohan, M. G. Schultz, D. J. Jacob, B. G. Heikes, and D. R. Blake, J. Geophys. Res., [Atmos.] 104, 5717 (1999).

${ }^{9}$ C. H. Kim, S. M. Kreidenweis, G. Feingold, G. J. Frost, and M. K. Trainer, J. Geophys. Res., [Atmos.] 107(D2), 4018 (2002).

${ }^{10}$ M. H. Lee, B. G. Heikes, and D. W. O'Sullivan, Atmos. Environ. 34, 3475 (2000).

${ }^{11}$ J. D. Crounse, K. A. McKinney, A. J. Kwan, and P. O. Wennberg, Anal. 
Chem. 78, 6726 (2006).

${ }^{12}$ L. G. Huey, P. W. Villalta, E. J. Dunlea, D. R. Hanson, and C. J. Howard, J. Phys. Chem. 100, 190 (1996).

${ }^{13}$ C. Amelynck, A. M. Van Bavel, N. Schoon, and E. Arijs, Int. J. Mass Spectrom. 202, 207 (2000).

${ }^{14}$ C. Amelynck, N. Schoon, and E. Arijs, Int. J. Mass Spectrom. 203, 165 (2000).

${ }^{15}$ J. D. Fast, B. de Foy, F. A. Rosas, E. Caetano, G. Carmichael, L. Emmons, D. McKenna, M. Mena, W. Skamarock, X. Tie, R. L. Coulter, J. C. Barnard, C. Wiedinmyer, and S. Madronich, Atmos. Chem. Phys. 7, 2233 (2007).

${ }^{16}$ O. B. Toon, D. O. Starr, E. J. Jensen, P. A. Newman, S. Platnick, M. R. Schoeberl, P. O. Wennberg, S. C. Wofsy, M. J. Kurylo, H. Maring, K. W. Jucks, M. S. Craig, M. F. Vasques, L. Pfister, K. H. Rosenlof, H. K.
Selkirk, P. R. Colarco, S. R. Kawa, G. G. Mace, P. Minnis, and K. E. Pickering, J. Geophys. Res., [Atmos.] 115, D00J04 (2010).

${ }^{17}$ D. J. Jacob, J. H. Crawford, H. Maring, A. D. Clarke, J. E. Dibb, L. K. Emmons, R. A. Ferrare, C. A. Hostetler, P. B. Russell, H. B. Singh, A. M. Thompson, G. E. Shaw, E. McCauley, J. R. Pederson, and J. A. Fisher, Atmos. Chem. Phys. 10, 5191 (2010).

${ }^{18}$ F. Paulot, J. D. Crounse, H. G. Kjaergaard, A. Kurten, J. M. St. Clair, J. H. Seinfeld, and P. O. Wennberg, Science 325, 730 (2009).

${ }^{19}$ R. A. Washenfelder, C. M. Roehl, K. A. McKinney, R. R. Julian, and P. O. Wennberg, Rev. Sci. Instrum. 74, 3151 (2003).

${ }^{20}$ J. R. Podolske, G. W. Sachse, and G. S. Diskin, J. Geophys. Res., [Atmos.] 108, 8792 (2003).

${ }^{21}$ H. Niki, P. D. Maker, C. M. Savage, and L. P. Breitenbach, J. Phys. Chem. 87, 2190 (1983) 